\title{
Facebook and the Neo-Nomads: $\Lambda$ Study of the Work of the Egyptian Comic Artist Muhammad Wahba El-Shennawy and the Use of Comics in History-Telling
}

\author{
Dina Muhammad Oleimy Halawa*
}

\section{Introduction}

Saving her father from heart attack, Ahmed's daughter, Samira, finds that the only option that she has is to get the medicine from one of the pharmacies located in Al-Attabah square which is far from her home. Going to the pharmacy marks the beginning of the 10-year-old Samira's journey which gets longer due to realizing that she lost her way while trying to get back home. This journey is the main plot of the Egyptian movie Life or Death. The theme of the journey allows the audience the chance to see how the city and the life of its people look in 1954. Throughout the different scenes the viewer sees the urban structure of the city with its fancy shops and cafes that were landmarks of downtown Cairo at that time. The audience also sees how the city's life style and how the 1954 Cairo was a cosmopolitan city that embraces people of different nationalities and different backgrounds. The aesthetic significance of a movie like Life or Death does not only lie in its purpose as a cinematic work that is produced to entertain the audience, but it also lies in its value as a documentary movie that presents the history of the city. As a documentary, the movie presents a true picture of the city and its life that surpasses its time to be revisited in the future. This paper aims at: first, investigating the concept of the neo-nomad and how it represents the new generation of artists who use social media channels to present their work. The work of the Egyptian comic artist Muhammad Wahba Al-Shennawy will be the focus of this paper. Second, examining the role of digital media platforms in disseminating and documenting the alternative historical discourses which allow the chance for the existence of a culture that produces new versions of truth that differs from the truth presented by the official culture. In this regard, the role of documentary comics will be examined to show how they build alternative archives which record events that are overlooked by the mainstream ideology.

\footnotetext{
* Assistant Lecturer at the British University in Cairo (BUE). Cairo Studies in English - 2019(2): https://cse.journals.ekb.eg/
} 


\subsection{Definitions}

1.1.1. Neo-nomads. When looking up the word in Urban Dictionary.com, it is found that the word neo-nomad means: "A new type of a nomad; a wanderer, someone without a fixed sense of belonging, digitally geared man on the move." Following this definition, there are two points to be noted: the first is that the term has an origin that requires a look back at its history. The second is to look at the current conditions that generate a new version of the term. According to the first point, the term neo-nomad is derived from the notion of the nomad that is presented by both Gilles Deleuze and Felix Guattari. Like the nomad, the three characteristics proposed by Deleuze and Guattari (1986) can be applied to the neo-nomad: the first represents the notion of "movement." The second correlates with the networks that the neo-nomad can create whereas the third lies in the nature of the "space" that the neo-nomad moves within (352). Regarding the first feature, the neo-nomad's movement is a flexible unrestricted movement which exempts him/her from having a fixed identity that restricts him/her to a certain community. The nonfixed identity and the flexible movement of the neo-nomad enables him/her to have the power of re-creating new structures that build new networks of connections. For a flexible movement to be realised, the nature of the space needs to be tackled. The neo-nomadic space is an "open" and "smooth" space that always allows the neo-nomad to "territorialize and deterritorialize" that space (Deleuze and Guattari 1986, 353).

Raising the question of the nomadic space and its nature highlights the current conditions and the new possibilities that lead to the generation of the notion of the neo-nomad. The second part of the definition drags attention to digitality which introduces the existence of cyberspace. The term was first coined by the American-Canadian fiction writer William Gibson who used the term repeatedly in his trilogy Neuromancer (1984), Count Zero (1986), and Mona Lisa Overdrive (1988). It is simply presented as a new realm that runs parallel to the real life. However, the ongoing flow of data is what constitutes cyberspace. It is, in other words, a "datascape" that is accessible by "jacking in" through the computer (Jordan 1999, 26). Despite the fact that the features that describe the nomad can be used to describe the life of neo-nomads, it is to be said that the existence of cyberspace provides its neo-nomads with more options that distinguish them from their predecessors -the nomads. As for the first feature, if Deleuze and Guattari (1986) state that the nomad has a free movement as he/she does not belong to the sedentary life imposed by the state, the neo-nomad's sense of freedom is greater as his/her corporeal existence dissolves once he/she enters cyberspace. Neo-nomads enter the new world of information through 
"uploading" their "consciousnesses" (Jordan 1999, 26) meaning that they are no longer tied to the boundaries of time and space that control the movement of bodies in real space. Regarding the second feature, since neo-nomads free themselves from restrictions of body, time and space, they are also able to free themselves from the powers of the fixed identity. The nomad in the real space has the same option; however, the multiple identities that the neo-nomad can create enable him/her to move flexibly and to build new connections with other virtual communities on a wide scale. The last feature that highlights the space highlights the significance of cyberspace in giving neo-nomads the chance to create their own "cyberculture" (Jordan 1999, 26) that questions the official culture of the state.

1.1.2. Neo-nomadic Knowledge. The neo-nomadic cyberculture produced in cyberspace gives neo-nomads power that challenges the imposed mainstream culture that they live under in real space. Hans A. Weiler (2002) states that knowledge and power are highly correlated: "it has confirmed that the linkages between knowledge and power are both very intimate and consequential" (1) as they "legitimatise" each other (3). The power of knowledge the neo-nomads generate does not only lie in challenging the dominant ideology, but also lies in the neo-nomad's ability to create a "diffusion" (Young-min 2007, 157) of cultures that represent different voices and perceptions. In other words, the fixed concept of a dominant monolithic culture is re-worked and changes to a state of "multiculturalism" (Young-min 2007, 157). Since neo-nomads leave their bodily existence and their fixed identities behind, then, the knowledge they produce can be considered as their new collective identity. The collective "bodies of knowledge" that are once connected and tied to one "centre" are now free and able to create its alternative culture (Lattas 1991, 98).

1.1.3. Historiography. In his A Companion to the Philosophy of History and Historiography, Aviezer Tucker (2009) defines historiography as "what historians write, about past events, about history" (13). Both P. Senkathir Selvi and Sheela Kirubakaram (2016) emphasise the fact that historians need sources in order to be able to come up with the "historiographic narratives" about past events (39). These sources, they claim, can be considered tools historians use so that they are able to collect that data (39). The two authors divide historical sources into two types: primary sources and secondary sources: "Primary sources (like sculptures, paintings, and monuments) are those which exhibit the occurrence of an historical event. Secondary sources (like books, journals, and 
encyclopedias) are those written by a person with the help of primary sources" (40). Selvi and Kirubakaram's quote raises a significant question that highlights the role that both texts and visual representations play in knowing and telling history. Carol E. Cleland (2009) draws the attention to another significant source that contributes to the process of history writing. This source lies in the "narrative accounts" that are told by the people who witness past events and who tell their own stories about them (quoted in Tucker 2009, 53).

1.1.4. Documentary Comics. Nina Mickwitz (2016) asserts that documentary comics play an important role in presenting history. The significance of documentary comics, she believes, lies in the fact that they are "....a mode of address through which audiences and readers are invited to accept that the persons, events, and encounters signified are actual rather than imagined" (7). Another importance of documentary comics as a genre is that they take part in enriching the "cultural memory" (Mickwitz 2016, 7). In this regard, Mickwitz (2016) states that cultural memory "comprises that body of reusable texts, images, and rituals specific to each society in each epoch, whose 'cultivation' serves to stabilize and convey that society's self-image" (60). In other words, cultural memory is part of the collective memory that unites the individuals under one community (Mickwitz 2016, 60).

\section{Material and Methodology}

\subsection{Material}

The Egyptian comic artist Muhammad Wahba El-Shennawy was born in Cairo, then, moved with his family to live in Zagazig. His movement from the capital city to one of the small villages in Egypt's countryside is considered a significant moment in his life as he realized that life in the capital and in the countryside is totally different. In 2013, Wahba started his project of drawing comics that depict the city of Cairo with all its details and depicts the lifestyle of its people. Since then, Wahba has extended his depiction of the city to other Egyptian cities that are away from the capital. Wahba's journey of producing comics has led to the production of six books. His books about Siwa and Alkoseir are best examples of comic books that do not only describe the two cities, but also show the life and histories of their people. Wahba states that the rationale behind producing documentary comics is that the urban structure of the Egyptian cities is in a rapid change which affects the lifestyle of their people. Therefore, it is important to document these ongoing changes and how they influence people. In addition, he believes that it is important to present the old histories of 
these cities as they are part of the collective and cultural identities of the Egyptian people. Regarding the tools that Wahba uses, he prefers to use ball point pens and small sketches which belong to the traditional school of drawing. He believes that using easy tools in drawing are the best options as they help him to draw rapidly. Besides the documentary comics that portray the city, Wahba draws comics that portray his everyday life activities and trips in and outside Egypt. The selected comics are the ones that Wahba posted on his Facebook page. He takes snapshots of scenes from his small sketches, then, he uploads them on his page. He states that the importance of sharing his comics on Facebook is that it helps him spread his perception of the city and document its history (Wahba, Facebook message to the author, June 27, 2019).

\subsection{Methodology}

The analytical framework is divided into two parts: the first part presents an analysis of Wahba's comics. The second part investigates the nature of the interaction between Wahba and his followers who respond to the comics posted as part of the process of knowledge produced in cyberspace. For the first part of the analysis, ten comics will be selected to discuss three major themes that Wahba depicts in his work: the first theme represents comics that capture the city and its life. The second theme presents an example of the unofficial history of the Nubian community which Wahba portrays in the comics he calls "The Nubians' Displacement". The third and last theme tackles comics that depict the everyday life events that occur in Wahba's life. Comics under this theme show Wahba's perceptions and feelings about the personal experiences related to the places and moments that he witnesses. For the second part, snapshots of samples are taken from the responses of Wahba's audience who use different ways to respond to his comics.

The rationale behind analysing the comics Wahba posts on Facebook goes with the aims of this paper as it: first, answers the question of whether can be considered a neo-nomadic comic artist or not. Second, reveals how the comics selected are good examples of how this genre takes part in disseminating and archiving historiographic narratives that reach a huge number of audience when posted on digital platforms. The answer to the first question recalls the comparison, mentioned in the introduction, between the nomad of the real space and the neo-nomad who roves cyberspace. In real space, Wahba relies on many sources while producing his comics. He relies on secondary sources (e.g. photographs and maps) that give him information about the places he depicts. Another way of getting more information about the places depicted is done 
through relying on primary sources. Wahba's primary sources are manifested in his visits to the places he describes in his comics. This ongoing movement to different places allows him to have a direct access to the locations, the histories and the life of their people. Wahba's travels allow him to undergo a state of "exteriority" that frees him from the "sovereignty" (Deleuze and Guattari 1986, 360) of the mainstream ideology. Wahba's flexible movement gives him the chance to look outside the imposed institutionalized coded models of the mainstream culture. Moving to the second aspect, which is relation, Wahba's travels enable him to build relations outside the boundaries of the sedentary society to see and communicate with other societies and to record their histories and culture that are disregarded by the official ideology. In other words, Wahba succeeds in going out of the fixed identity to see and create new identities that go with the new experiences he undergoes. Another aspect that makes Wahba a good representation of the nomad lies in his use of space. In real space, Wahba succeeds to create a smooth and open space that guarantees him the easy and flexible movement from one place to another. Moving to cyberspace, Wahba is considered a neo-nomad comic artist. The notion of movement is embodied in Wahba's uploading and sharing of his comics on Facebook. Uploading and sharing his comics indicates the fact that he leaves his meatspace behind to be a neo-nomad who uploads information in the digital datascape. Posting comics on Facebook highlights the second aim which emphasises the role of digital media in spreading alternative discourses. Sharing comics enables Wahba to reach more audience who are able to have an access to the comics posted without being restricted by the limits of time and space. In other words, Facebook enables the audience to reach both the artist and his comics easily. The uploaded comics are a good example of how Wahba makes use of the open digital space to create a cultural sphere that allows his audience to respond to the comics posted. The cultural sphere that the comics create leads to the creation of an alternative cyberculture that challenges the mainstream culture.

The analytical approach that this paper follows is based on the iconological method that is proposed by the German art historian Erwin Panofsky. Panofsky (1955) defines iconology as "a method of interpretation which arises from synthesis rather than analysis" (32). For synthesizing and understanding the meaning of the art work, there must be a look at the model that Panofsky suggests for the interpretation of an artistic work. Panofsky's model is based on three steps: a. Pre-iconographic description which is considered the basic step in examining and interpreting the image. The pre-iconographic description is both "factual and expressional" (Panofsky 1955, 28). It is factual as it is concerned 
with the representations of "natural objects" that exist in real world. The expressional factor is achieved when the "mutual relations" between the objects represented are investigated to produce meaning (Panofsky 1955, 28). The primary and natural representation of objects are called "artistic motifs" (Panofsky 1955, 28). b. Iconographical analysis connects the "combination of artistic motifs" with certain "themes and concepts" that are manifested in "images, stories, and allegories" (Panofsky 1955, 29). In this stage, the iconographical meaning of the image surpasses one's realization of the motifs and the events that rely on the practical experience to knowing the specific themes and stories that represent the "intrinsic meaning" that relates the image to the different contexts behind the image produced (Panofsky 1955, 35). c. Iconological interpretation is considered the last step in Panofsky's model. It embodies the correlation between "logos" (ideas and discourse) and "images" (images and pictures) (Muller 2011, 288). Panofsky (1955) states that the iconological interpretation is connected with the "synthetic intuition" (39). Panofsky (1955) emphasises that the job of the art historian is to connect the primary/natural artistic motifs with the contexts that are expressed through the stories and allegories of the art work to synthesize its meaning: "The art historian will have to check what he thinks is the intrinsic meaning of the work... against what he thinks is the intrinsic meaning of as many other documents... [which are] bearing witness to the political, poetical, religious, philosophical, and social tendencies of the personality, period or country under investigation" (39). In the light of the theory of iconology and the model proposed by Panofsky, an iconological context analysis will be applied to Wahba's comics. The analysis works on three contexts: the first is the motifs or the "form of the visual" (Muller 2011,292). The second represents the "production context" whereas the third is the "reception context" (Muller 2011, 292). According to Muller (2011), the motif context has many forms "ranging from architecture, sculpture to graphic art (for example, caricatures), photography, film, television, video and electronic images" (292). The second level of context analysis focuses on the production which influences the form and the meaning of the art work. There are six types of production contexts: "the artistic", the "commercial", the "journalistic", the "scientific", the "political", and the "private" (Muller 2011, 293). The third and last level of context analysis focuses on the interpretation of the image (Muller $2011,294)$. In this stage, the reaction of the recipient is examined. 


\section{Analysis and Results}

Before dealing with the analysis of the themes Wahba depicts in his comics, there are two general remarks that can be applied on all the comics selected in this paper. The first remark highlights the compositional structure that is related to the first level of context analysis -the form. It is noted that Wahba's comics fall under the category of graphic art. Wahba uses simple lines; however, it is obvious that he has an eye for details. In his comics, the pictorial depiction of the details of the scene are the only guidance that leads the audience to the purpose of the comics produced. The comics selected are good examples of Wahba's reliance on visuals rather than using words or texts to deliver his idea. The depiction of details and the focus on producing mute images (that do not include texts) have their influence on the way the audience sees and reads the comics. As mentioned in the material section, Wahba's comics are based on the depiction of live scenes and moments that he witnesses. Therefore, the option of producing colorful comics does not exist as black becomes the dominant colour in all the comics. Wahba's reliance on using one colour to produce his comics relates to the time factor which pushes him to draw his scenes rapidly so that he can capture the moment. The second remark emphasises the connection between the producer and the "intrinsic meaning" of the art work. The artistic production context denotes that the artist is the producer of his work. Thus, the audience does not only see the scenes depicted in the comics through Wahba's eyes, but he/she has an access to the artist's practical experience that is implicitly conveyed through the comics produced. The analysis of the themes will emphasise more on how Wahba uses comics to document different types of histories using simple and clear motifs.

\subsection{Theme 1: The City}

Jens Balzer (2010) asserts the fact that one of the basic features that distinguishes comics from the classical works of art lies in its "modernity" that replaces the notion of the "fixed" gaze with a "loose" and "moving" gaze (7). The power of the comics, Balzer continues, lies in its ability to "decentralize" the image (7). The concept of the moving gaze is manifested in the scenes of the city in examples 3.1 and 3.2 which show two bird-eye scenes of the old and contemporary architecture in Cairo. The first scene captures Al-Azhar area where the mosque of Muhammad Abu Dahab and its minaret are obviously seen. The second scene shows modern blocks revealing the crowdedness of the city. The two scenes raise the question of the gaze which influences the way the audience sees them. Depicting the two scenes from a higher position is a good 
example of using the "panoptic" gaze that allows Wahba to provide his audience with a panoramic view of different areas of the city. On the level of the preiconographic description, the panoptic position that Wahba takes while drawing the two scenes allows him to focus on specific details that he wants the audience's gaze to focus on. For instance, in the first scene, the focus is directed to the mosque of Muhammad Abu Dahab and not Al-Azhar mosque that lies besides Abu Dahab's mosque. This explains why the mosque and its minaret occupies the majority of the space in the comic. In scene 3.2, the focus is distributed on all the buildings where nothing specific drags the artist's attention. The common factor in the two scenes, however, is that the audience sees the "factual" representation of the natural objects that are expressed through the comics produced. Moving to the iconographical analysis, the intrinsic meaning that the two scenes convey is that they both express two different historical periods that Cairo embraces: the first belongs to the Islamic Fatimid Cairo with its fancy architecture whereas the second refers to the present moment that reveals the huge movement towards the modern urban architecture. The iconological interpretation of the two scenes highlights the symbolic significance of the panoptic gaze and its connection with Wahba's position. Ole Frahm (2010) states that the panoptic gaze's power lies in its ability to show the control over the city: "The panoptic gaze cleans the city of all contradictions [as] it becomes a timeless and thus controllable subject" (43). As a person who lives in one of the villages in Egypt, understanding the nature of life in the city puts him in a struggle of power that is conquered through the panoptic gaze which gives him a full control over the details of the scene he is depicting. The total control over the city details in the two scenes enables Wahba to have control ofwhat to show and what to hide. Scene 3.2 is an example which, as all the windows are blind, presents the city as a "space without depth" where the audience has no access to see the details and lives that lie behind these windows (Frahm 2010, 40).

The panoptic gaze changes to a more detailed gaze that depicts the details of the city life and its people. In example 3.3, Wahba moves from the panoptic position to acquire the one of the "urban flâneur" (Balzer 2010, 7). The two comics presented in examples 3.3 and 3.4 introduce the "dispersed" gaze as the technique of reading them. Scene 3.3 shows one of the most important squares in Cairo which is Tahrir square that was the stage for all the significant moments in the history of Egypt. Scene 3.4 shows a close-up view of one of the cafes in downtown Cairo. On the pre-iconographic level, the two scenes express the practical experience of Wahba when he visits the two places. Unlike the comics 
in example 1, the objects depicted in the two comics are clearer and more detailed than the holistic view of the buildings as Wahba allows the audience an access to details of the everyday life of the city's inhabitants. Like Wahba, the audience turns to be a flaneur whose gaze is "distracted" (Balzer 2010, 26) all over the scenes to grasp the details depicted in each comic. In scene 3.3, the audience's gaze focuses on the background to see the edifices that are considered the landmarks of the Tahrir square. Cairo tower, the flag in the middle, and the famous Hilton and Nile Ritz Carlton in the background enable the audience to recognise the place depicted in the comic. At the same time, the gaze is directed to the foreground to see the crowd and the ongoing movement of the pedestrians in the square. Like scene 3.3, the gaze in scene 3.4 is decentralised as the audience focuses on the actions that take place in the background and to the details of the location and he/she also focuses on the details of the group of friends who gather in the café. If the iconographical analysis of the scenes in examples 3.1 and 3.2 bring the historical context to light through depicting the past and the present, the scenes in examples 3.3 and 3.3 highlight the stories of the social context that narrows the focus on depicting how the people in the city spend their leisure time. The two comics portray the people's use of and interaction with the urban spaces they live within. They show how the city's urban spaces are structured and how the movement of the people are controlled in these spaces. The controlled/restricted movement of the people reflects the nature of life in the city where people are tied to strict structures that control their movement. The iconological interpretation of the city comics drags attention to the comic's ability to create alternative unofficial discourses that record both the history of the places and the people that live in the city.

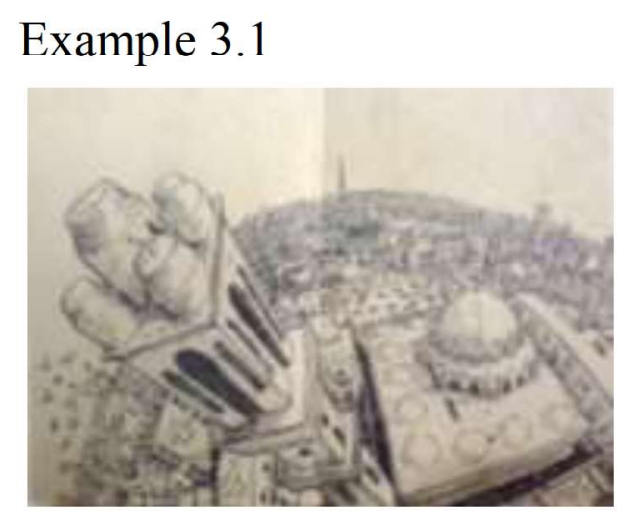

https://www.facebook.com/photo.php?fbid=2583251908357116\&set=pb.100000169971315.$2207520000.1554026730 . \&$ type $=3 \&$ theater 


\section{Example 3.2}

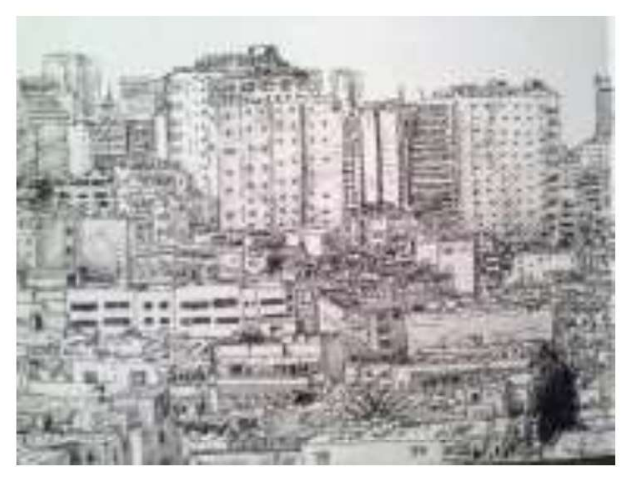

https://www.facebook.com/photo.php?fbid=2298527866829523\&set=pb.100000169971315.$2207520000.1554027184 . \&$ type $=3 \&$ theater

\section{Example 3.3}

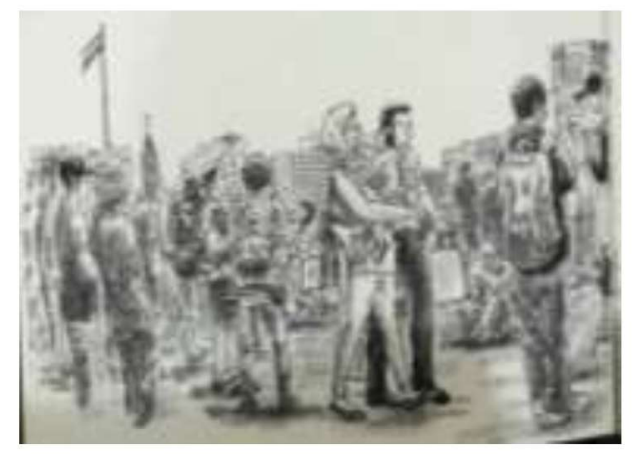

https://www.facebook.com/photo.php?fbid=2203585642990413\&set=pb.100000169971315.$2207520000.1554019940 . \&$ type $=3 \&$ theater

\section{Example 3.4}

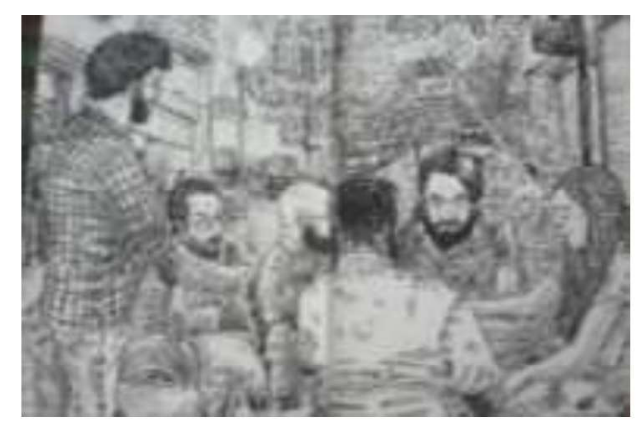

https://www.facebook.com/photo.php?fbid=2167689626580015\&set=pb.100000169971315.$2207520000.1554028567 . \&$ type $=3 \&$ theater 


\subsection{Theme 2: Unofficial History}

Political iconography relates art to the political leaders whose "zeal for creating something new" urges them to impose their "visions" through artistic production (Muller 2010, 289). The focus of political iconography is on investigating the relationship between the use of visual imagery and the political vision that turns political leaders to active actors and that later takes part in shaping the mainstream ideology which gives the state power over its people. The comic that depicts the displacement of the Nubians during Nasser's rule turns Wahba to an active political actor whose project presents an alternative perception of the Nubians' displacement that took place in the sixties. In other words, Wahba, through his comic, succeeds in creating an unofficial historiographic discourse that narrates a moment in the history of a marginalised community whose history is not tackled in the official historical discourse of the mainstream ideology. On the level of the pre-iconographic description, the visual details of the comic present a panoramic view of the moment of displacement when Nasser's government forced the Nubians to leave their houses to resettle in another place. Scenes 1 and 2 are parts of the 24-meter-long panorama that Wahba shares on his Facebook page. Despite the fact that Wahba does not upload the whole comic, the scenes shared on Facebook decentralise the audience's gaze as it will be distracted to grasp all the details depicted in the comic. Scene 1 shows a close-up view of some Nubians who are waiting for the boats to take them whereas scene 2 depicts the boats while moving to the resettlement area. In the background a view of the Nubians' houses can be seen to enhance the sense of belonging and to show the deep connection that Nubians have towards their land. The iconographic analysis of the comic brings the social and cultural contexts of the Nubian community to light. In an interview with Mossad Herky, the chairman of the Egyptian Nubian Foundation, journalist Farah El-Akkad (2016) reveals how Nubians are unable to forget the tragedy of the displacement which deprives them from their right in the lands of their ancestors. Herky asserts that since the traumatic event of the displacement of the Nubian population, the Nubians feel "marginalised and isolated" from the society. On the level of the social context, the ongoing marginalisation of the state, despite the promises to return, turns the Nubians to be a closed community that keeps its perceptions and norms shared between its members. The social marginalisation restricts the cultural sphere that expresses the Nubian heritage to the members of the community to the extent that, as Herky states, puts the Nubian culture under the risk of dying. Wahba's comic is an attempt to preserve a moment in the history of the Nubian community that the official historical 
discourse overlooks. It also plays the role of the reminder to the Egyptians of an important event that took place in the modern history of Egypt. The iconological interpretation of the comic pinpoints the fact that the image, as Carol Armstrong emphasises, can be used as a "site of resistance" (quoted in Rose 2001, 10).

Resistance is evident in the idea of producing an alternative version of truth that differs from the one that is imposed by the mainstream ideology. In other words, Wahba, through this comic, succeeds in producing a historical narrative that negotiates, and might challenge, the one provided by the official discourse. In other words, Wahba succeeds in creating an alternative cultural sphere that leads to the production of a new archive that includes the deselected truths that are neglected by the mainstream culture. Another iconological interpretation of the comic drags attention to the link between archives and documentary comics. According to Mickwitz (2016), the significance of archives lies in the important role they play in formulating the cultural memory of the society (61). Thus, as Mickwitz assures, the dominant system has the power to decide on what needs to be recorded and preserved and what to be overlooked (61). The documentary comic that Wahba produces highlights the power of documentary comics as "performative narratives" that present the individual's account of the deselected stories and events that are neglected by the official archives (Mickwitz 2016, 65). In Wahba's case, the comic is a good example of the neo-nomadic knowledge that re-works the official history by creating an alternative unofficial archive that questions the official archive. In other words, sharing the comic on the Facebook, allows Wahba to play the role of the historian who takes part in creating a cyberculture that goes along with the official discourse of the dominant ideology.

\section{Scene 1}

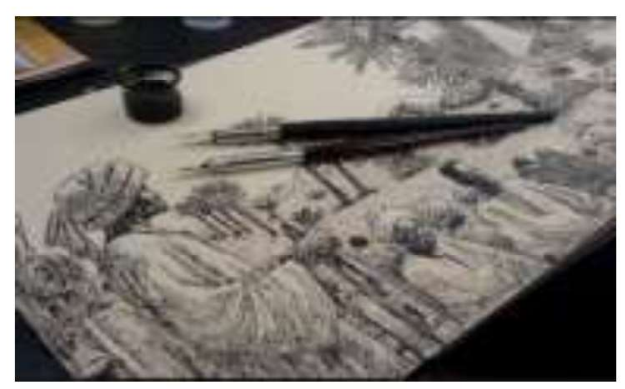

https://www.facebook.com/photo.php?fbid=1814075251941456\&set=a.588983604450633\&type=3 \&theater 


\section{Scene 2}

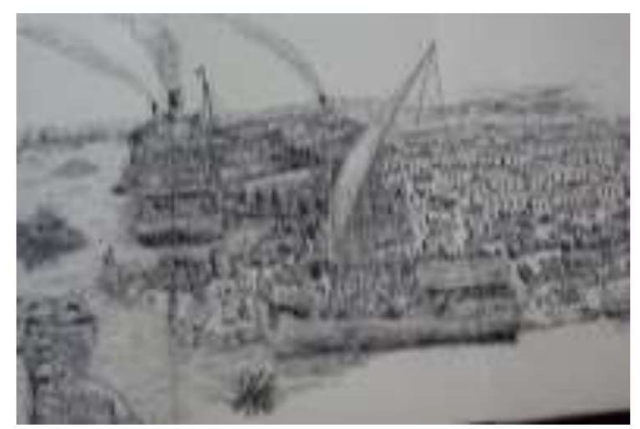

https://www.facebook.com/photo.php?fbid=1821176994564615\&set=a.205161049499559\&type=3 \&theater

\subsection{Theme 3: Personal History}

Apart from depicting the unofficial history of marginalised communities, Wahba drags attention to another type of history which portrays the personal life of ordinary individuals. The comics in example 3.3.1 exemplify the shift to the depiction of the details of Wahba's everyday life. Back to the dispersed gaze, the pre-iconographic description of the two comics present a different compositional structure that is based on both literal and visual representations of Wahba's ideas. Despite the fact that iconography does not "incorporate language", inserting words/texts within the image lets letters take an "iconographic quality" as the area of the image becomes the "canvas for words" (Balzer 2010, 26). What Wahba does in the two comics is that words become an "integral" (Balzer 2010, 26) part of the graphic design. As a result, the audience's gaze will be distracted as he/she has to simultaneously observe and watch the objects and read the words/texts included in them. The watching-reading technique, therefore, becomes part of the aesthetic interpretation of the work. The iconographical analysis of the two comics emphasises the stories that both the literal and visual representations weave. These stories give the audience an access to what Wahba feels and thinks about the people he meets in his everyday life.

In the first comic, Wahba speaks about his students in one of the workshops he gives. The visual images depict the students while drawing their comics. Inserting the texts that accompany the visuals are considered the clue that helps in understanding the comic. They show how Wahba is impressed by his students whose comics enable them to express the different ideas and meanings they have in mind. The second comic portrays Wahba's friends and the different things that he learns from them. The text divides the second comic to four panels; each adds a new piece of detail about Wahba's friends. The first panel, for instance, 
tackles his friend Laila whom Wahba praises and states that she always supports him. In the second panel, Wahba talks about the good things he acquires from his friends through the different situations they have together. The third and the fourth panels are a continuation of Wahba's narration of the positive influence that his friends have on him.

Like the comic above, the iconological interpretation of the two comics emphasises the significant role which documentary comics play as archives that record real events. The comics below assure the fact that the notion of comics as archives are not only limited to the collective history that represents the collective memory of a certain community, but they can also do the function of individual archives that assert the ordinary individual's ability to record their own personal stories. As a neo-nomad, sharing the two comics on Facebook enhances Wahba's identity as a user who has the chance to voice his ideas freely on cyberspace.

\section{Example 3.3.1:}

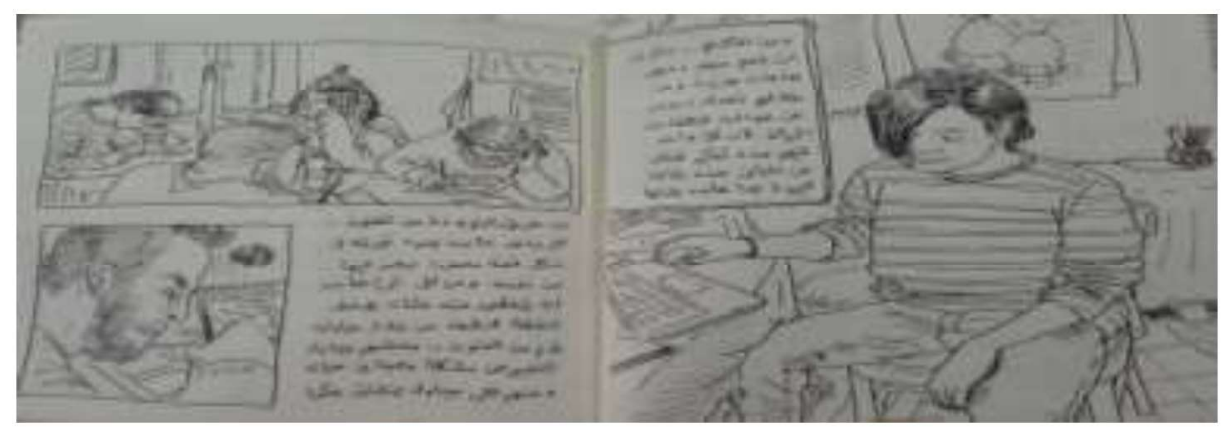

https://www.facebook.com/photo.php?fbid=1958132660869047\&set=pb.100000169971315.$2207520000.1542032501 . \&$ type $=3 \&$ theater

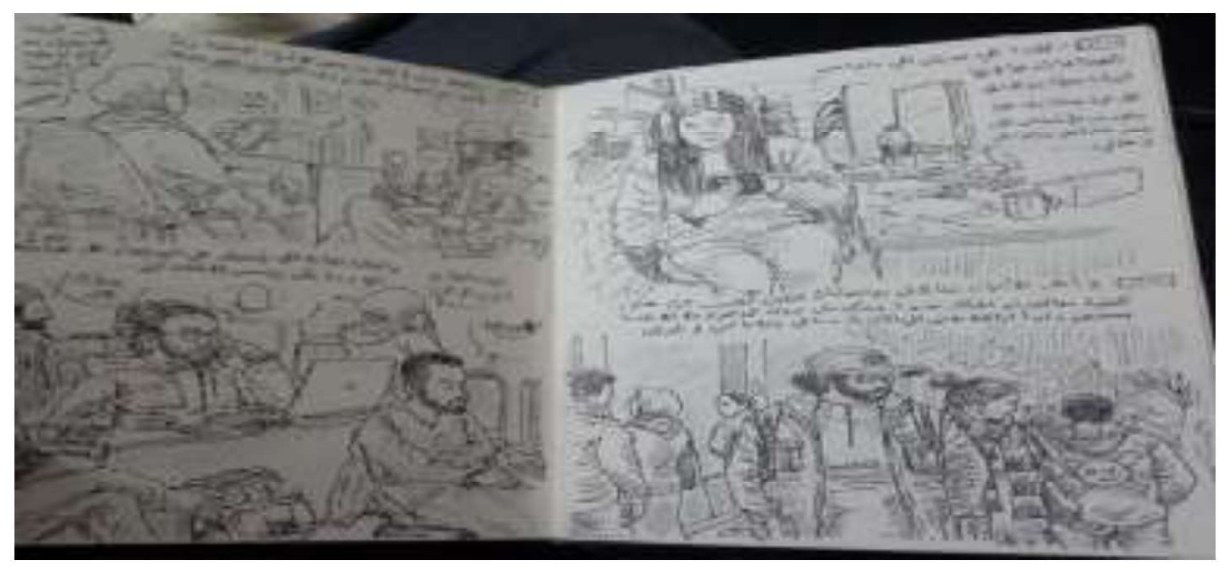

https://www.facebook.com/photo.php?fbid=2039935279355451\&set=pb.100000169971315.$2207520000.1566354191 . \&$ type $=3 \&$ theater 


\subsection{Audiencing}

"Everyone who uses a computer is a multi-media maker," this is what Rodrick Coover (2011) says when empahsising how the new "media tools" change the way users "engage" with the different content created or shared on digital media platforms (617). Through sharing his comics on Facebook, Wahba is able to create an active interactive environment that allows his audience the chance to comment and interact with the comics posted. The 26.000 followers are now able to access Wahba's comics and react to them. Unlike virtual reality environments, that are based on creating simulations of real milieus, Wahba's usage of Facebook is limited to uploading snapshots of the comics that are already drawn on paper. Thus, the followers' responses to the comics posted are controlled by the options that Facebook provides for its users. Followers can either send quick responses through using the different characters that reveal their own opinion or respond textually through sending their comments on the comics. Another form of interaction is manifested in sharing the comics posted. The discrepancy between the numbers of the shared comics shows to what extent the audiences interact with the theme and meaning of the comic so that they want to share it to their personal pages. The three forms of interaction patterns that Facebook has require a thorough look at the users' behaviour on social media networks. According to Cheonsoo Kim and Sung-Un Yang (2017), there are three categories of social media behaviours: "consuming", "contributing", and "creating" (442). The first category involves the "participative behaviours" of seeing and reading the material, then, using the like/dislike characters. The second category represents the users' contribution by sharing or commenting on the material posted. The third category involves "producing and publishing content" (Kim and Yang 2017, 442). Measuring the level and the effectiveness of three categories shows that the lowest interaction behaviour is the first one whereas the highest is the last one as it requires more "commitment" and more "cognitive" reading of the material (Kim and Yang 2017, 443).

Examples 3.4.1 and 3.4.2 are samples of the followers' responses to the two comics depicting Al-Azhar area comic and the Nubians' displacement. There are also screenshots that present the pages/users who share the comic on their personal pages. In example 3.4.1, there are 340 followers who participated through using Facebook characters that show their liking and impressiveness. The sense of impressiveness moves to a higher level as other 20 followers decided to respond through commenting on the comic. The comments are expressed textually or visually (e.g. like the user who shows his liking to the comic by using the thumb up symbol). Moving to the sharing option, there are 
70 followers who shared the comic on their personal pages. Kim and Yang (2017) emphasise that despite commenting and sharing fall under the same category of the behaviour of "contributing", sharing takes a higher level than commenting as it is linked to the notion of "self-presentation" (443). They explain that when the user comments on a post, the post appears on the News Feed. On the other hand, when the post is shared, it does not only exist on the News Feed, but it also goes to the user's "profile page" (443). Sharing the post on the profile page is considered the user's way of expressing the ideas and concepts he/she believes which will, accordingly, be part of how other users know and evaluate this user: "when sharing a post, users are more committed to assessing its value regarding the self than when commenting on a post" (443). The first follower shares the comic on his page and it gets 18 liking symbols and is shared by another user whereas the second sharing attempt of the same comic receives 4 liking symbols only. However, it is noted that in the second attempt the user contributes to the comic by adding a note followed by three hearts as to assert that the comic reminds him of past memories related to the place depicted.

The note added to the comic is taken from Ahmed Mekky's song Wa'fet Nasyt Zaman (https://www.youtube.com/watch? $\mathrm{v}=\mathrm{DjLpLaGPANM}$ ) that is shot in old Cairo's neighborhoods. The combination between the comic shared and the part taken from the song indicates that Wahba's comic is re-worked which gives it a new meaning that relates it to personal memories. In example 3.4.2, the comic on the Nubians' displacement receives 908 liking symbols and 44 comments that express the same message of the symbols. 48 followers share the comic on their personal pages. The first screenshot shows that the comic is shared on a page called For the Love of Comics and Animation! (https://www.facebook.com/ groups/948764031885579/about/) which is a public group for amateurs and comic artists who are free to post the comics they produce. In the second screenshot, the comic is shared by a page called Nubia (https://www. facebook.com/NubiaPage/). If the first page has about 1000 followers, the second page guarantees Wahba's comic a better chance for disseminating his work as it is followed by over 1000.000 users. Nubia is a page that was released in 2010 as an online platform that represents the Nubian culture and history. The page uses different forms of multimedia that acknowledge acquaint users with details of the Nubian heritage. The act of sharing in Wahba's case plays a significant role when connected to the "way of seeing" (Rose 2001, 13) as it could be considered part of the iconological interpretation of the comics posted. Sharing the comics highlights several aspects that enhance their significance when posted online: the first aspect correlates with the question of dissemination 
and the ability of digital media platforms to reach a wider range of viewers. The act of sharing the comics on other pages leads them to be viewed by more users who also respond, by symbols or comments, on the comics. The second aspect relates the sharing to the notion of the user-generated content which is considered a basic feature that distinguishes cyberspace as a medium from the other traditional mediums. When Wahba's followers share his comics on other pages, they go beyond their purpose as documentary comics to gain new meanings. In example 3.4.1, the iconographical analysis of the comic is linked to the personal memories and history of the follower who shared it. Adding part of Mekky's song drags attention to the concept of intertextuality that helps in generating new meaning and purpose of the comic. The comic in example 3.4.2 recalls the usage of the image as a "site of resistance" (Rose 2001, 10). Sharing the comic on a page that supports and defends the Nubian rights enhances the political significance of the visual representation that portrays the Nubians' displacement. In other words, the knowledge that the comic presents is reworked by putting it in the new context that expresses a culture that opposes the official culture.

Example 3.4.1

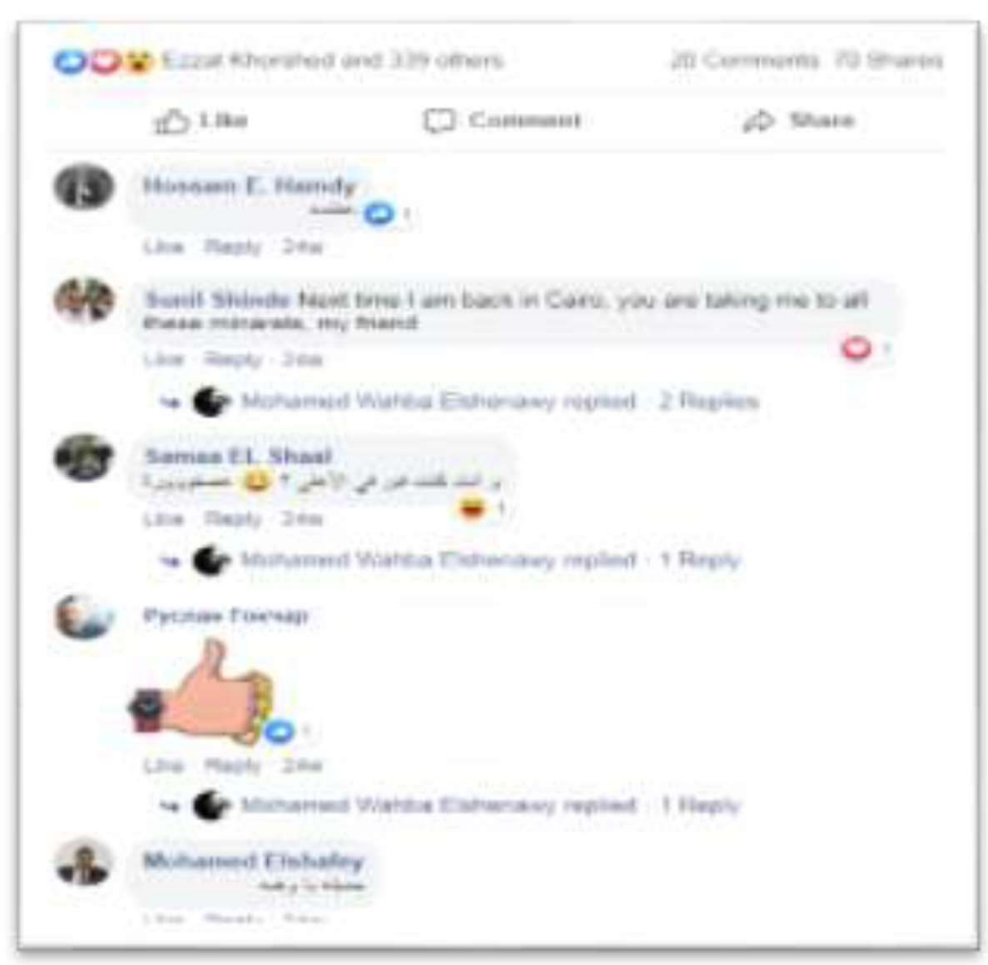


Facebook and the Neo-Nomads

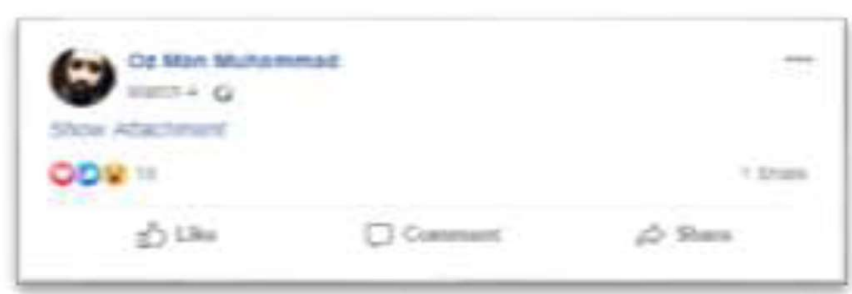

https://www.facebook.com/photo.php?fbid=2583251908357116\&set=pb.100000169971315.$2207520000.1554026730 . \&$ type $=3 \&$ theater

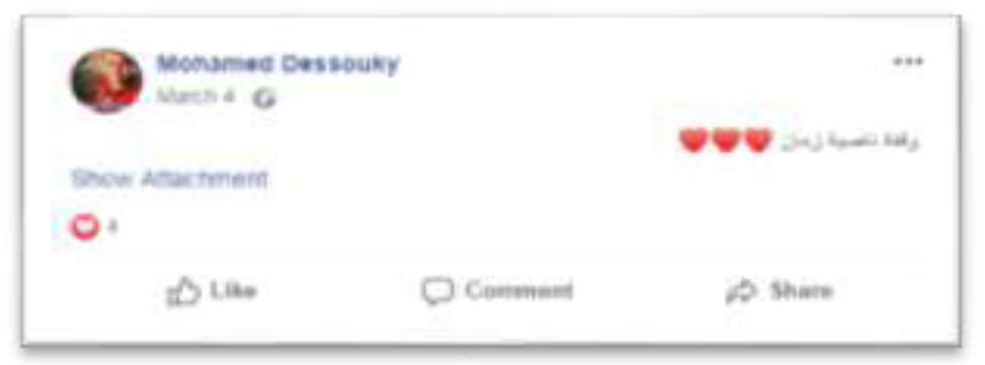

https://www.facebook.com/photo.php?fbid=1814075251941456\&set=a.588983604450633\&type=3 \&theater

\section{Example 3.4.2}

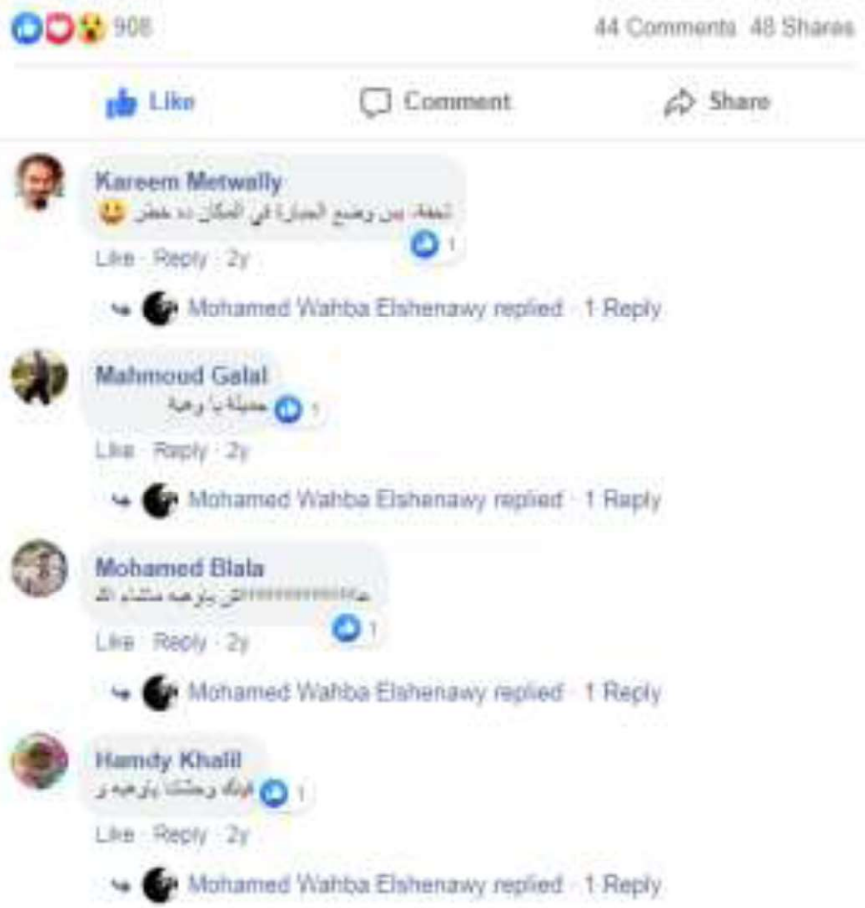




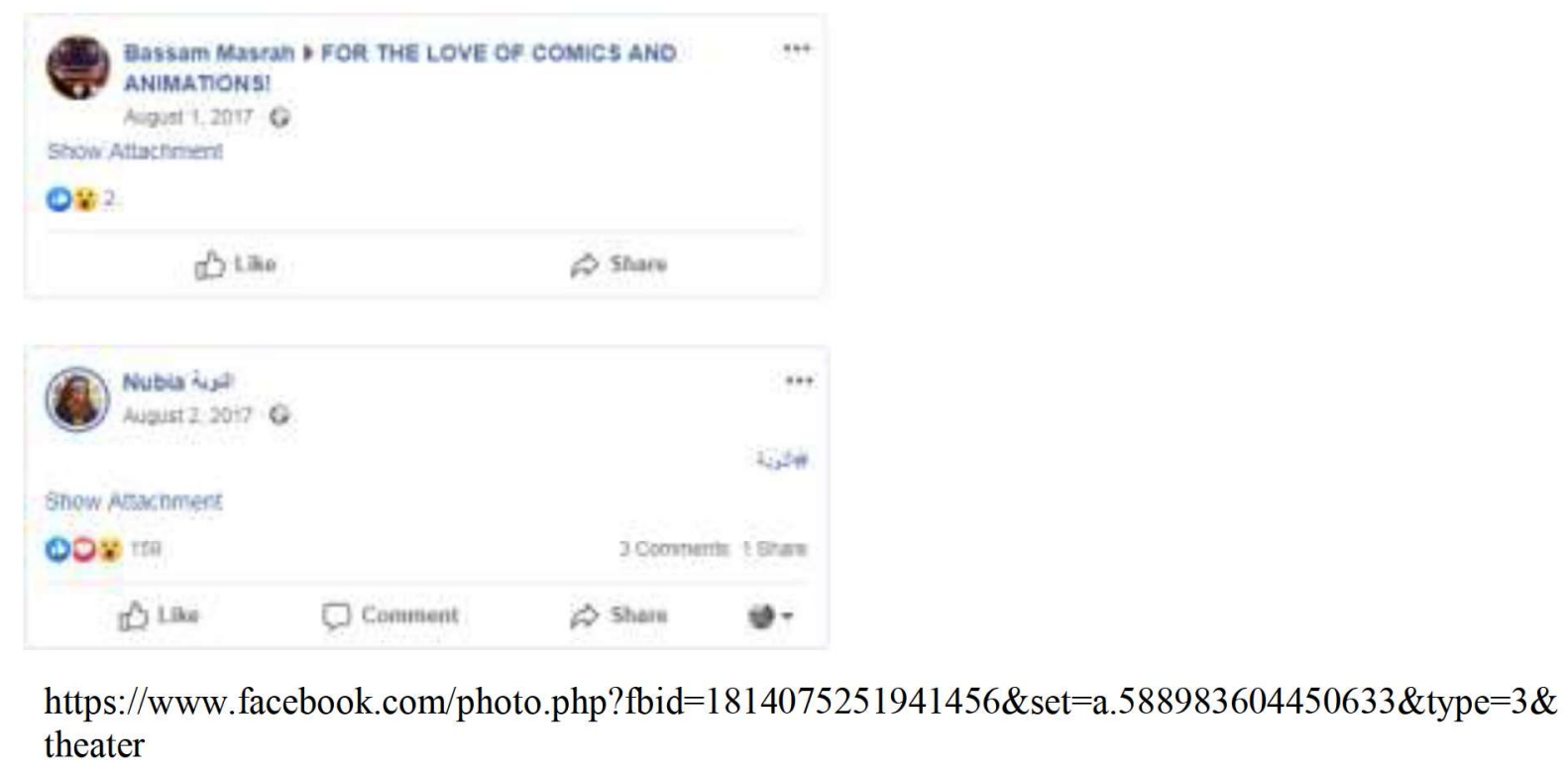

\section{Conclusion}

With the growing use of digital space, it becomes obvious that official discourses are no longer the only accepted forms of knowledge that gather subjects. These subjects are now able to create their own discourses and knowledge that express their thoughts and beliefs. This paper shows how Wahba is an example of the neo-nomad comic artists who through sharing his comics on Facebook lives in a state of "exteriority" that allows him the chance to escape the boundaries of the real "controlled" space and of his bodily existence to the new "smooth" space of the digital world. The paper also examines the role that social media networks play in spreading the alternative historical discourses and how these discourses pave the way for the existence of cyberculture. The findings of the paper asserts that comics are not only a genre connected with imaginary events, but they can also describe true events and depict the life of real people. In this paper, it is shown that comics can be considered historical accounts that narrate stories about events and people whose stories are overlooked by the dominant culture. The first limitation of this study is that it limits it scope to the analysis of the comics that Wahba posted on his Facebook. Future research can broaden the focus of the study to include the print work of Wahba. The second limitation is that the paper builds its analysis to the responses of the comics posted based on the likes, comments, and shares found on Wahba's page. Future research could hold interviews with the followers to know more information about how they deal and think about the comics posted. 


\section{Works Cited}

Balzer, Jens. 2010. “"'Hully Gee, I'm a Hieroglaphy" -- Mobilizing the Gaze and the Invention of Comics." In Comics and the City: Urban Space in Print, Picture, and Sequence, edited by Jorn Ahrens and Arno Meteling, 19-31. New York: The Continuum International Publishing Group Inc.

Coover, Roderick. 2011. "Interactive Media Representation." In The Sage Handhook for Visual Research Methods, edited by Fric Margolis and Iuc Pauwels, 283-297. London: Sage Publications Ltd.

Deleuze, Gilles, and Felix Guattari. 1986. A Thousand Plateaus: Capitalism and Schizophrenia. Translated Brian Massumi. Minneapolis, London: University of Minnesota Press.

El-Akkad, Farah. 2016. "52 Years After Displacement, Scars of Loss Remain for Nubians." Egypt Today, October 25, 2016.

https://www.egypttoday.com/Article/10/3182/52-Years-After-isplacementScars-Of-Loss-Remain-For-Nubians.

For the Love of Comics. 2016. Facebook, June 30, 2019.

https://www.facebook.com/groups/948764031885579/about/

Frahm, Ole. 2010. "Every Window Tells a Story: Remarks on the Urbanity of Early Comic Strips." In Comics and the City: Urban Space in Print, Picture, and Sequence, edited by Jorn Ahrens and Arno Meteling, 32-44. New York: The Continuum International Publishing Group Inc.

Jordan, Tim. 1999. Cyberpower: The Cultural and Politics of Cyberspace and the Internet. London: Routledge.

Kim, Cheonsoo, and Sun-Un Yang. 2017. "Like, Comment, and share on Facebook: How Each Behavior differs from Other." Public Relations Review 43, (2017): 441-449.

https://www.sciencedirect.com/science/article/abs/pii/S0363811116300157

Lattas, Andrew. 1991. "Primitivism in Deleuze and Guattari's "A Thousand Plateaus." Social Analysis: The Journal of social and Cultural Practice, no. 30 (December): 98-115. https://www.jstor.org/stable/23164529.

Mekky, Ahmed. 2017. "Wa'fet Nasyt Zaman." YouTube, June 30, 2019. https://www.youtube.com/watch?v=DjLpLaGPANM.

Mickwitz, Nina. 2016. Documentary Comics: Graphic Truth-Telling in a Skeptical Age. London: Palgrave Macmillan.

Muller, Marion G. 2011. "Iconography and Iconology as a Visual Method and Approach." In The Sage Handbook for Visual Research Methods, edited by Eric Margolis and Luc Pauwels, 283-297. London: Sage Publications Ltd. 
Panofsky, Erwin. 1955. Meaning in the Visual Arts. New York: Doubleday Anchor Books.

Rose, Gillian. 2001. Visual Methodologies. London: Sage Publications Ltd.

Selvi, Senkathir P. and Sheela Kirubakaram. "Data Collection with Special Reference to Historical Research-A Study." International Journal of Management Research and Social Science (IJMRSS) 3, no. 2 (June): 39-41.

Tucker, Aviezer. 2009. A Companion to the Philosophy of History and Historiography. London: Blackwell Publishing Ltd.

Weiler, Hans A. 2002. "Whose Knowledge Matters? Development and Politics of Knowledge." Stanford University, July 2002.

https://web.stanford.edu/ weiler/Texts09/Weiler_Molt_09.pdf.

Yun Young-Min Young-Min, Yun. 2007. "Birth of Neo-nomadism in Korea." Institute for Social Development and Policy Research (ISDPR) 36, no. 2 (December): 153-175. http://www.jstor.org/stable/deveandsoci.36.2.153. 